\title{
CONDICIONAMENTO FISIOLÓGICO E VIGOR DE SEMENTES DE MAXIXE ${ }^{1}$
}

\author{
PAULO COSTA ARAÚJO², SALVADOR BARROS TORRES ${ }^{3}$, CLARISSE PEREIRA BENEDITO4 \\ EMANOELA PEREIRA DE PAIVA²
}

\begin{abstract}
RESUMO - O condicionamento fisiológico é uma técnica para a embebição controlada das sementes que permite a ativação dos processos metabólicos da germinação, evitando a emissão da raiz primária, propiciando uniformização e melhor desempenho das plantas em campo. O objetivo nesta pesquisa foi verificar os efeitos do hidrocondicionamento sobre a germinação e vigor de sementes de maxixe. Para isso, duas cultivares Do Norte e Nordestino, representadas por três lotes, foram hidrocondicionadas em papel toalha, a $20{ }^{\circ} \mathrm{C}$, até atingirem $33,5 \%$ de água (Nordestino) ou $38,1 \%$ (Do Norte). Em seguida, parte das sementes foram secadas a temperatura ambiente $\left(28-34{ }^{\circ} \mathrm{C}\right)$ e umidade relativa do ar de $45-55 \%$, até atingirem teores de água de 7,0 a $8,5 \%$. O potencial fisiológico das sementes foi determinado em laboratório, avaliando-se percentagem e índice velocidade de germinação. Em casa de vegetação, determinou-se a percentagem e índice de velocidade de emergência, altura e massa seca das plântulas aos 14 dias após a semeadura. $\mathrm{O}$ hidrocondicionamento promove efeitos benéficos sobre as características de germinação e vigor nos lotes das duas cultivares avaliadas.
\end{abstract}

Termos para indexação: Cucumis anguria L., hidrocondicionamento, vigor.

PRIMING AND SEED VIGOR IN GHERKINS (Cucumis anguria L.)

\begin{abstract}
Priming is a technique for controlling seed hydration that allows activation of germination metabolic processes but avoiding the emission of the primary root and providing uniformity and better plant performance in the field. The objective of this study was to evaluate the effects of hydropriming on germination, emergence and seedling development in gherkins. Gherkin seeds of the Do Norte and Nordeste cultivars, represented by three lots, were primed at 20 ${ }^{\circ} \mathrm{C}$ on paper towels until they reached $33.5 \%$ (Nordeste) or $36.6 \%$ (Do Norte) water content. Part of the seeds were dried at room temperature $\left(28-34{ }^{\circ} \mathrm{C}\right)$ and a relative humidity of $45-55 \%$ until water content was 7.0 to $8.5 \%$. The physiological potential of the seeds was determined in the laboratory by evaluating germination rate and speed. Later, the percentage and emergence speed index, height and dry mass of seedlings 14 days after sowing were determined in the greenhouse. Hydropriming benefitted the germination and vigor characteristics of both cultivars.
\end{abstract}

Index terms: Cucumis anguria L., hydropriming, vigor.

\footnotetext{
${ }^{1}$ Submetido em 28/09/2010. Aceito para publicação em 15/03/2011.

${ }^{2}$ Aluno da graduação em Agronomia, Universidade Federal Rural do Semiárido (UFERSA), e-mail: pauloaraujo85@hotmail.com; emanuelappaiva@hotmail.com
}

${ }^{3}$ EMPARN/UFERSA, Departamento de Ciências Vegetais, C.P. 137, CEP 59625-900, Mossoró, RN, e-mail: sbtorres@ufersa.edu.br

${ }^{4}$ Doutoranda em Agronomia/Fitotecnia (UFERSA), bolsista da Capes, e-mail: clarissepb@yahoo.com.br 


\section{INTRODUÇÃO}

O sucesso da produção olerícola depende dentre outros aspectos, de aceitável estabelecimento de plântulas no campo, fator este diretamente relacionado com a germinação das sementes. O período compreendido entre a semeadura e o estabelecimento das plântulas é fase crucial da produção olerícola. Assim, sementes de alta qualidade e condições que permitam máxima germinação em menor tempo possível, com máxima uniformidade de plântulas é sem dúvida uma busca constante daqueles envolvidos na cadeia produtiva de hortaliças (Nascimento, 2005).

$\mathrm{O}$ maxixeiro (Cucumis anguria L.), de origem africana, é uma cucurbitácea altamente rústica, cultivada em pequena escala, sendo o fruto apreciado em diversas partes do Brasil (Filgueira, 2003).

A produção de sementes de maxixe no Brasil é considerada baixa quando comparada com a de outras hortaliças. Alguns entraves contribuem para o aumento nos custos de produção desta cultura, entre eles, a utilização de sementes locais, obtidas de plantas espontâneas que aparecem nos cultivos tradicionais como feijão e hortas domésticas. Como essas sementes são produzidas sem nenhum manejo, sua qualidade fisiológica é normalmente baixa. Além disso, poucos estudos foram realizados no que diz respeito aos aspectos agronômicos do maxixe, portanto, a produção de semente comercial desta cultura é pequena (Medeiros et al., 2010).

O condicionamento fisiológico de sementes é uma técnica que tem sido apresentada como promissora que visa à melhoria do desempenho das sementes, com melhor uniformidade e velocidade de emergência de plântulas, principalmente sob condições climáticas adversas. A técnica consiste na embebição das sementes em água, solução salina ou osmótica, ou em substratos umedecidos, para a ativação dos processos metabólicos essenciais à germinação, sem ocorrer emergência da raiz primária (fase III). Desse modo, o condicionamento fisiológico se dirige as fases I e II de embebição para germinação, durante as quais ocorre ação de mecanismo de reparo de macromoléculas danificadas e de estruturas celulares, fazendo com que as sementes germinem de forma sincronizada (Bray, 1995).

Dentre as técnicas de condicionamento fisiológico, o hidrocondicionamento apresenta algumas vantagens em relação as demais técnicas por ser um método mais simples, barato e não utilizar reagentes ou equipamentos sofisticados (Fijikura et al., 1993). Alguns fatores estão envolvidos na eficiência do condicionamento fisiológico como o potencial fisiológico inicial das sementes, genótipo, período de tratamento, tamanho das sementes e outros.

Após o condicionamento, as sementes atingem teores de água relativamente elevados e inadequados para a conservação do potencial fisiológico durante o armazenamento. Desta maneira, a secagem deve ser conduzida de maneira adequada, para minimizar a possibilidade de reversão dos efeitos benéficos do tratamento (Marcos Filho e Kikuti, 2008). Além disso, a secagem após o condicionamento é desejável, pois evita expor as sementes aos riscos de danos mecânicos provocados pelos equipamentos de semeadura (Balbino e Lopes, 2006).

A eficiência do condicionamento fisiológico foi avaliada em sementes de várias espécies de hortaliças como pimentão (Kikuti et al., 2005), tomate, melão, melancia e berinjela (Nascimento, 2005), couve-flor (Marcos Filho e Kikuti, 2008) e cenoura (Pereira et al., 2009).

Desta forma, considerando-se a ausência de informações sobre o uso do condicionamento fisiológico em sementes de maxixe, objetivou-se avaliar os efeitos dessa técnica sobre a germinação e vigor destas sementes.

\section{MATERIAL E MÉTODOS}

O trabalho foi conduzido no Laboratório de Análise de Sementes e em casa de vegetação do Departamento de Ciências Vegetais (DCV) da Universidade Federal Rural do Semiárido (UFERSA), durante o período de setembro a novembro de 2009. Para isso, utilizaram-se sementes de duas cultivares de maxixe, Do Norte e Nordestino, cada uma representada por três lotes. As sementes foram adquiridas em pontos comerciais nas cidades de Mossoró/ RN (Do Norte, lotes 1 e 2; Nordestino, lote 3), Guaraparí/ ES (Do Norte, lote 3) e Petrolina/PE (Nordestino, lotes 1 e 2), cujos teores iniciais médios de água das sementes foram de $8,5 \%$ para os lotes da Do Norte e $7 \%$ para os da Nordestino.

Preliminarmente foi determinada a curva de embebição das sementes, utilizando-se duas repetições de aproximadamente $0,130 \mathrm{~g}$ para cultivar Nordestino e 0,140 g para cultivar Do Norte. As sementes foram colocadas em copos plásticos contendo $150 \mathrm{~mL}$ de água destilada a $20{ }^{\circ} \mathrm{C}$. Após intervalos de tempo predeterminados (de hora em hora nas nove primeiras horas, de duas em duas 
horas até o final do primeiro dia e três horas no segundo dia), as sementes foram retiradas da água, secadas superficialmente com papel de filtro, pesadas e colocadas novamente para embeber conforme método descrito por Baskin e Baskin (2001). Esse procedimento foi realizado até que não fossem observadas alterações de peso das sementes (36 horas).

Para o hidrocondicionamento, os três lotes das duas cultivares foram embebidas entre duas camadas de papel toalha, com quantidade de água destilada equivalente a 2,5 vezes o peso do substrato seco, a temperatura de $20{ }^{\circ} \mathrm{C}$, até atingirem 33,5\% de água (Nordestino, após 24 horas) ou 36,6\% (Do Norte, após 18 horas). Para determinar o teor de água foi utilizado o método da estufa a $105{ }^{\circ} \mathrm{C} \pm 3{ }^{\circ} \mathrm{C}$ durante 24 horas (Brasil, 2009). A secagem das sementes foi realizada em temperatura ambiente $\left(28-30{ }^{\circ} \mathrm{C}\right)$ e umidade relativa do ar de $45-55 \%$, até atingirem teores próximos aos iniciais $(7,0-8,5 \%)$. Parte das sementes hidrocondicionadas não foi submetida à secagem, enquanto as testemunhas permaneceram com o teor inicial de água, conforme descrito anteriormente.

Os parâmetros usados para a avaliação foram: germinação $(\mathrm{G})$, índice de velocidade de germinação (IVG), emergência (E), índice de velocidade de emergência (IVE), altura da parte aérea das plântulas, massa da matéria seca da parte aérea das plântulas.

Germinação - conduzida em laboratório, conforme recomendações das Regras para Análise de Sementes (Brasil, 2009). Para isso, utilizou-se caixas plásticas transparente $(11,0 \times 11,0 \times 3,0 \mathrm{~cm})$, sobre duas folhas de papel mata-borrão umedecido com água destilada $(2,5$ vezes a massa do substrato) em quatro repetições de 50 sementes, a temperatura constante de $32{ }^{\circ} \mathrm{C}$ e 8 horas de luz, sendo as avaliações aos quatro e oito dias após a semeadura.

Índice de velocidade de germinação - registrouse diariamente o número de sementes germinadas até o décimo quarto dia e calculado pela fórmula proposta por Maguire (1962), na qual IVE $=\mathrm{N} 1 / \mathrm{D} 1+\mathrm{N} 2 / \mathrm{D} 2+\ldots+$ $\mathrm{Nn} / \mathrm{Dn}$, onde: IVE = índice de velocidade de emergência de plântulas; $\mathrm{N}=$ número de plântulas emergidas e computadas da primeira à última contagem; $\mathrm{D}=$ número de dias da semeadura da primeira a última contagem.

Emergência de plântulas - realizado em casa de vegetação, utilizando-se quatro repetições de 50 sementes para cada cultivar e lote de sementes, que foram semeadas em bandejas de poliestireno contendo 200 células, com substrato comercial Plantmax e regadas diariamente. Aos
14 dias após a semeadura foi avaliada a percentagem de plântulas normais (Nakagawa, 1994).

Índice de velocidade de emergência - seguiuse a mesma metodologia do índice de velocidade de germinação, de acordo com (Maguire, 1962).

Altura da parte aérea de plântulas - aos quatorze dias após a semeadura foi mensurada a altura das plantas com o auxílio de uma régua graduada em centímetros, tomando-se a medida do colo até plúmula, para isso foram eliminadas as plantas que se encontravam nas bordas da bandeja.

Massa de matéria seca da parte aérea de plântulas - após determinação da altura, as plântulas de maxixe foram colocadas em sacos de papel e levadas a estufa a $65{ }^{\circ} \mathrm{C}$ por 48 horas e posteriormente foram pesadas em balança eletrônica com precisão de 0,001 g (Nakagawa, 1999).

O esquema fatorial foi $3 \times 3$, sendo três tratamentos e três lotes para as cultivares Nordestino e Do Norte. As médias foram comparadas pelo teste de Tukey ao nível de $5 \%$ de probabilidade. Para a análise estatística, utilizouse o programa estatístico SISVAR for Windows versão 4.1 (Ferreira, 2000), considerando separadamente cada cultivar, em delineamento inteiramente casualizado com quatro repetições.

\section{RESULTADOS E DISCUSSÃO}

Na Figura 1 observa-se o gráfico da evolução do processo de embebição das sementes nas cultivares Nordestino e Do Norte. As primeiras manifestações do processo de embebição das sementes para as duas cultivares ocorreram logo após 1 hora do contato das sementes com água, caracterizado pelo intumescimento e aumento significativo do tamanho e massa.

$\mathrm{Na}$ cultivar Nordestino a massa inicial era de $0,128 \mathrm{~g}$ e grau de umidade inicial de 7,0\%, e após 1 hora a massa era $0,159 \mathrm{~g}$ e o grau de umidade passou para $26,6 \%$. $\mathrm{Na}$ Do Norte, a massa inicial era de 0,142 g e grau de umidade inicial de $8,5 \%$, após 1 hora de embebição a massa atingiu $0,179 \mathrm{~g}$ e o grau de umidade a $27,4 \%$, desse modo as duas apresentaram comportamento semelhante com relação a velocidade de absorção de água. Portanto, é possível observar claramente a caracterização da fase I da curva de absorção nas duas cultivares. Bewley e Black (1994) caracterizam tal fase como sendo bastante rápida, responsabilizando a absorção de água nesta fase como conseqüência do 
potencial matricial dos vários tecidos da semente e, por isso, independe da semente ser dormente ou não (a não ser, que se trate de dormência por impermeabilidade da casca à água) e de estar viva ou não. De acordo com Carvalho e Nakagawa (2000) a fase I possui duração de uma a duas horas.

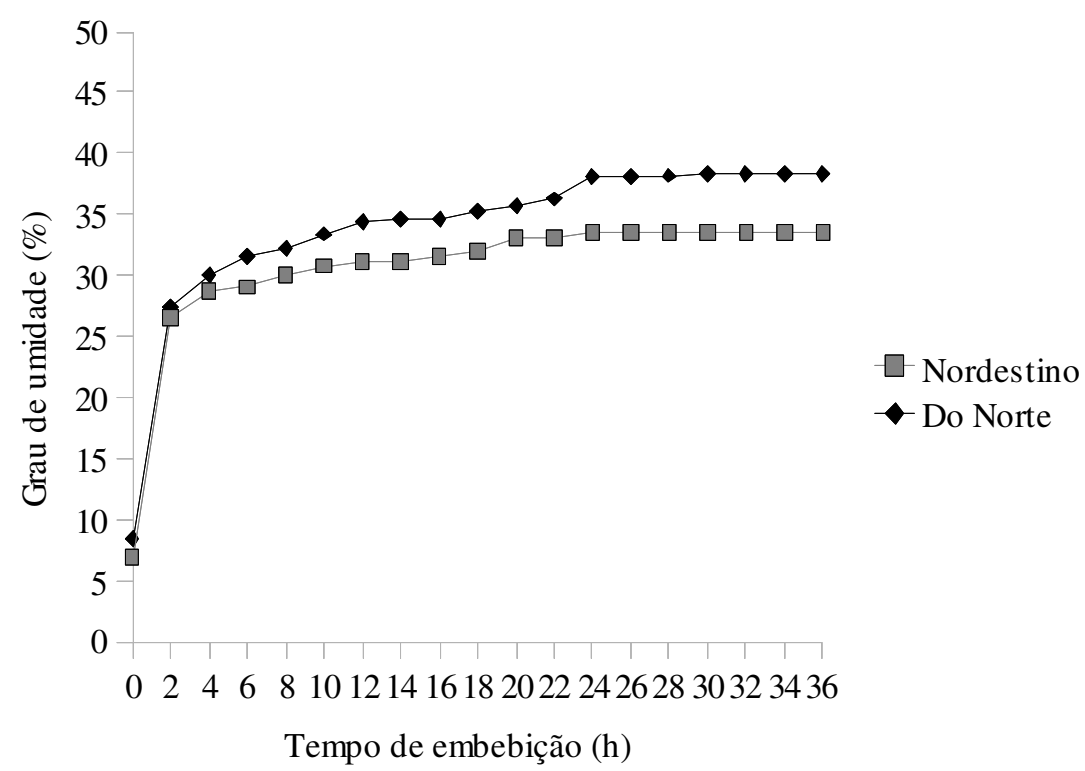

FIGURA 1. Curva de embebição de sementes de maxixe (Cucumis anguria L.), cultivar Nordestino e Do Norte, mantidas sob temperatura de $20^{\circ} \mathrm{C}$.

A fase II caracterizada pelas reduções drásticas da velocidade de hidratação e da intensidade de respiração prolongou-se por aproximadamente 32 horas em ambas as cultivares, com a estabilização de peso de amostras das duas cultivares avaliadas. De acordo com Bewley e Black (1994), é necessária uma diminuição da absorção de água para a mobilização das substâncias que foram desdobradas na fase I da região de reserva para os tecidos meristemáticos. No presente trabalho, a fase III, caracterizada como fase de absorção ativa de água, a qual só atingem as sementes não dormentes e viáveis, não ficou nítida, provavelmente devido as pesagens terem sido levadas até 36 horas após o início do teste, teria sido necessário estender os registros de absorção de água até a emissão da raiz primária.

A análise de variância dos dados detectou resultados significativos tanto para os efeitos dos lotes e tratamentos utilizados, indicando que os lotes apresentavam diferenças quanto ao vigor e, que os testes foram adequados para avaliar a qualidade fisiológica das sementes. Dessa forma, a porcentagem de germinação, índice de velocidade de germinação, emergência de plântulas, índice de velocidade de emergência e altura de plântulas identificaram os lotes 1 e 3 como os de maior vigor para a cultivar Nordestino. $\mathrm{Na}$ cultivar Do Norte, também foi possível visualizar diferença significativa entre os lotes através de todas as características avaliadas, observando-se que o lote 1 apresentou desempenho superior aos lotes 2 e 3 (Tabelas 1 e 2).

Para a germinação houve efeito significativo dos métodos de condicionamento para as duas cultivares estudadas. $\mathrm{Na}$ cultivar Nordestino, o hidrocondicionamento seguido de secagem, apresentou média superior embora não tenha diferido do hidrocondicionamento e, este não tenha diferido da testemunha. Já na cultivar Do Norte, o hidrocondicionamento foi estatisticamente superior aos demais tratamentos. Alguns autores afirmam que, geralmente o condicionamento fisiológico não consegue promover alterações na porcentagem de germinação, algumas pesquisas confirmam tal afirmação, 
como Kikuti e Marcos Filho (2008) em sementes de couveflor e Gurgel Júnior (2009) com sementes de pepino, onde não encontraram diferenças significativas para porcentagem de germinação utilizando os mesmos tratamentos desta pesquisa. Porém, alguns autores apresentaram resultados semelhantes aos verificados neste trabalho; para sementes de berinjela (Trigo e Trigo, 1999), melão (Nascimento e Aragão, 2002), melão, melancia e tomate (Nascimento, 2005) sendo que o hidrocondicionamento favoreceu a germinação em temperaturas sub-ótimas.

TABELA 1. Valores médios e coeficientes de variação (\%) referentes à porcentagem de germinação (G) e índice de velocidade de germinação (IVG) de três lotes de sementes de maxixe (Cucumis anguria L.), cultivares Nordestino (C1) e Do Norte (C2), submetidos ao hidrocondicionamento seguido ou não por secagem.

\begin{tabular}{|c|c|c|c|c|c|c|c|c|c|c|c|c|c|c|}
\hline \multirow{2}{*}{\multicolumn{2}{|c|}{ Teste }} & \multicolumn{4}{|c|}{ Hidrocondicionamento } & \multicolumn{4}{|c|}{$\begin{array}{c}\text { Hidrocondicionamento + } \\
\text { Secagem }\end{array}$} & \multicolumn{4}{|c|}{ Testemunha } & $\begin{array}{l}\mathrm{CV} \\
(\%)\end{array}$ \\
\hline & & L1 & $\mathrm{L} 2$ & L3 & Média & L1 & L2 & L3 & Média & L1 & $\mathrm{L} 2$ & L3 & Média & \\
\hline \multirow{2}{*}{$\mathrm{C} 1$} & $\mathrm{G}(\%)$ & $84 a$ & $79 a$ & $83 a$ & $82 \mathrm{AB}$ & $95 \mathrm{a}$ & $78 b$ & $89 \mathrm{a}$ & $87 \mathrm{~A}$ & $87 \mathrm{a}$ & $78 \mathrm{ab}$ & $74 b$ & $80 \mathrm{~B}$ & 6,81 \\
\hline & IVG & $9,7 \mathrm{a}$ & $7,2 b$ & $9,2 \mathrm{a}$ & $8,7 \mathrm{~A}$ & $10,5 \mathrm{a}$ & $6,5 \mathrm{~b}$ & $9,2 \mathrm{a}$ & $8,7 \mathrm{~A}$ & $9,2 \mathrm{a}$ & $6,0 \mathrm{~b}$ & $7,7 \mathrm{a}$ & $7,6 \mathrm{~B}$ & 11,3 \\
\hline \multirow{2}{*}{\multicolumn{2}{|c|}{ Teste }} & \multicolumn{4}{|c|}{ Hidrocondicionamento } & \multicolumn{4}{|c|}{$\begin{array}{c}\text { Hidrocondicionamento }+ \\
\text { Secagem }\end{array}$} & \multicolumn{4}{|c|}{ Testemunha } & $\begin{array}{l}\mathrm{CV} \\
(\%)\end{array}$ \\
\hline & & L1 & $\mathrm{L} 2$ & L3 & Média & L1 & L2 & L3 & Média & L1 & L2 & L3 & Média & \\
\hline \multirow{2}{*}{$\mathrm{C} 2$} & $\mathrm{G}(\%)$ & $98 \mathrm{a}$ & $66 b$ & $69 \mathrm{~b}$ & $78 \mathrm{~A}$ & $87 \mathrm{a}$ & $66 \mathrm{a}$ & $31 b$ & $61 \mathrm{~B}$ & $96 a$ & $56 b$ & $41 b$ & $64 \mathrm{AB}$ & 20,7 \\
\hline & IVG & $15,5 \mathrm{a}$ & $7,7 \mathrm{~b}$ & $6,7 \mathrm{~b}$ & $10,0 \mathrm{~A}$ & $12,7 \mathrm{a}$ & $8,25 b$ & $3,0 \mathrm{c}$ & $8,0 \mathrm{~B}$ & $11,0 \mathrm{a}$ & $5,2 \mathrm{~b}$ & $4,0 \mathrm{~b}$ & $6,7 \mathrm{~B}$ & 16,9 \\
\hline
\end{tabular}

Letras minúsculas: comparações entre médias de lotes; letras maiúsculas: comparação entre tratamentos dentro de cada lote (teste de Tukey, $5 \%$ de probabilidade).

TABELA 2. Valores médios e coeficientes de variação (\%) referentes à emergência de plântulas (E), índice de velocidade de emergência (IVE), altura de plântulas (AP) e massa da matéria seca de plântulas (MS) de três lotes de sementes de maxixe (Cucumis anguria L.), cultivares Nordestino (C1) e Do Norte (C2), submetidos ao hidrocondicionamento seguido ou não por secagem.

\begin{tabular}{cccccccccccccccc}
\hline \multirow{2}{*}{ Teste } & \multicolumn{3}{c}{ Hidrocondicionamento } & \multicolumn{3}{c}{ Hidrocondicionamento + } & & Testemunha & CV \\
$(\%)$
\end{tabular}

Letras minúsculas: comparações entre médias de lotes; letras maiúsculas: comparação entre tratamentos dentro de cada lote (teste de Tukey, 5\% de probabilidade). 
Para o índice de velocidade de germinação, com a cultivar Nordestino os melhores resultados foram obtidos com sementes hidrocondicionadas, seguidas ou não de secagem, em relação à testemunha. De acordo com Caseiro (2003), o hidrocondicionamento promove efeitos benéficos sobre o índice de velocidade de germinação o que beneficia o estabelecimento do estande em campo. Os tratamentos que induzem a iniciação metabólica pela hidratação das sementes têm a finalidade de elevar a taxa e a velocidade de germinação, produzir uniformidade de emergência e aumentar a capacidade das plântulas em resistir aos efeitos adversos do ambiente (Motta e Silva, 1997; Marcos Filho, 2005). Na cultivar Do Norte, apenas as sementes hidrocondicionadas apresentaram maiores índices de velocidade de germinação em relação aos demais tratamentos, provavelmente isso ocorreu devido aos lotes 2 e 3 da cultivar Do Norte apresentarem baixo vigor em relação ao lote 1. Peñazola e Eira (1993) observaram que sementes de tomate da cv. Nemadoro e Rio Grande provenientes de lotes de potencial fisiológico inferior necessitaram de um período maior de embebição do que as de alto vigor para concluir a fase II do processo de germinação. Lima e Marcos Filho (2009), afirmam que o hidrocondicionamento é favorável a velocidade de germinação dos lotes de alto e médio vigor, mas os lotes de baixo vigor não se beneficiam com essa técnica.

As duas cultivares não apresentaram diferença estatística entre si quanto à emergência de plântulas. Estes resultados estão de acordo com os obtidos por Gurgel Júnior et al. (2009), onde não foi verificado diferença entre o hidrocondicionamento, seguido ou não de secagem em relação à testemunha para emergência de plântulas. Caseiro (2003) trabalhando com sementes de cebola, cv. Petroline, hidrocondicionadas e com diferentes métodos e períodos de armazenamento não encontrou vantagem no tratamento pré-condicionador na porcentagem de plântulas emergidas.

Para o índice de velocidade de emergência, os lotes das duas cultivares apresentaram resultados semelhantes, onde o hidrocondicionamento teve efeito estatisticamente superior aos demais tratamentos, mostrando assim novamente efeito positivo do hidrocondicionamento das sementes no vigor (Tabela 2). Esses resultados confirmam as observações efetuadas por Giurizatto et al. (2008) com sementes de soja e por Marcos Filho e Kikuti (2008) em sementes de couve-flor, nos quais a expressão do vigor pela velocidade de germinação e de emergência de plântulas, indicou vantagem do hidrocondicionamento.
Apesar das informações existentes ainda há dúvidas com relação ao efeito da secagem em sementes condicionadas fisiologicamente. De maneira geral, tem sido verificado após a secagem das sementes, um pequeno decréscimo na velocidade de germinação, no entanto, este fato é esperado, pois inclui o período necessário para reembebição das sementes durante o processo de germinação (Caseiro, 2003). Segundo Trigo e Trigo (1999), a rápida emergência das sementes em campo é uma situação bastante vantajosa, porque acarreta menor período de exposição das sementes a fatores adversos do ambiente, após a semeadura.

Constatou-se efeito significativo dos tratamentos para altura de plântulas nas duas cultivares. Na cultivar Nordestino as sementes hidrocondicionadas apresentaram altura de plântulas estatisticamente superior, embora não tenha diferido do hidrocondicionamento seguido de secagem. Já para a cultivar Do Norte, as sementes hidrocondicionadas apresentaram alturas de plântulas estatisticamente superior aos demais tratamentos. Para as sementes dessa cultivar o hidrocondicionamento seguido de secagem afetou negativamente na altura das plântulas (Tabela 2).

Os tratamentos utilizados interferiram significativamente na massa seca de plântulas da cultivar Nordestino. O hidrocondicionamento teve efeito positivo no acúmulo de massa seca das plântulas, a testemunha apresentou menores médias. Já na cultivar Do Norte, o hidrocondicionamento também favoreceu o acúmulo de massa seca de plântulas, porém o hidrocondicionamento seguido de secagem não diferiu estatisticamente da testemunha (Tabela 2). O fato de sementes condicionadas apresentarem plântulas com maior acúmulo de matéria seca pode ser devido aos processos metabólicos que ocorrem durante o condicionamento em níveis que não permitem, para a maioria das espécies, o início da divisão e expansão celular, mas que induzem uma prolongada capacidade de síntese de proteínas o que proporciona um balanço metabólico mais favorável, gerando incrementos não na germinação, mas também no crescimento das plântulas e no acúmulo de biomassa (Trigo et al., 1999). De acordo com Nery et al. (2005), plântulas que apresentam menor teor de matéria seca apresentam-se como menos vigorosas sendo, portanto, menos tolerante ou resistente às condições adversas do campo.

O hidrocondicionamento nesta pesquisa promoveu efeitos benéficos nas duas cultivares avaliadas, verificando-se também que o efeito dessa técnica é bastante influenciada pelo nível de vigor inicial dos lotes. 
Contudo, através do hidrocondicionamento as sementes estarão menos expostas às condições ambientais adversas após a semeadura. No tocante a secagem, verifica-se que para cultivos comerciais a secagem após o hidrocondicionamento é imprescindível. Portanto, é interessante que sejam estudadas metodologias de secagem após o hidrocondicionamento de sementes de maxixe em função dos efeitos benéficos permitidos pelo hidrocondicionamento, e da essencialidade da secagem após hidrocondicionamento para cultivos comerciais.

\section{CONCLUSÕES}

O hidrocondicionamento promove efeitos benéficos sobre as características de germinação e vigor de sementes de maxixe.

\section{AGRADECIMENTOS}

Os autores agradecem ao Conselho Nacional de Desenvolvimento Científico e Tecnológico (CNPq) pelo apoio financeiro e, principalmente, pela bolsa de estudo concedida ao primeiro autor.

\section{REFERÊNCIAS}

BALBINO, E.; LOPES, H.M. Efeitos do condicionamento fisiológico e da secagem na germinação e vigor de sementes de cenoura. Revista Brasileira de Sementes, v.28, n.1, p.1-8, 2006.

BASKIN, C.C.; BASKIN, J.M. Seeds: ecology, biogeography, and evolution of dormancy and

germination. New York: Academic Press, 2001. 666p.

BRASIL. Ministério da Agricultura, Pecuária e Abastecimento. Regras para análise de sementes. Ministério da Agricultura, Pecuária e Abastecimento. Secretaria de Defesa Agropecuária. Brasília, DF: Mapa/ ACS, 2009. 395p.

BRAY, C.M. Biochemical processes during the osmopriming of seeds. In: KIEGEL, J.; GALILI, G. (Ed.). Seed development and germination. New York: Marcel Dekker, 1995. cap. 28. p.767-789.

BEWLEY, J.D.; BLACK, M. Seeds: physiology of development and germination. 2.ed. New York: Plenum Press, 1994. 445p.

CARVALHO, N.M.; NAKAGAWA, J. Sementes: ciência, tecnologia e produção. 4.ed. Jaboticabal: Funep, 2000. 588 p.

CASEIRO, R.F. Métodos para o condicionamento fisiológico de sementes de cebola e influência da secagem e armazenamento. 2003. 109f. Tese (Doutorado em Fitotecnia) - Escola de Agricultura Luiz de Queiroz (USPESALQ), Piracicaba. 2003.

FERREIRA, D.F. Sistema de análises de variância para dados balanceados. Lavras: UFLA, 2000. (SISVAR 4. 1. pacote computacional).

FUJIKURA, Y.; KRAAK, H.L.; BASRA, A.S.; KARSSEN, C.M. Hidropriming, a simple and inexpensive priming method. Seed Science and Technology, v.21, n.3, p.639642, 1993.

FILGUEIRA, F.A.R. Novo manual de olericultura: agrotecnologia moderna na produção e comercialização de hortaliças. 2.ed. Revista e ampliada, Viçosa: UFV, p.358, 2003.

GIURIZATTO, M.I.K.; ROBAINA, A.D.; GONÇALVES, M.C.; MARCHETTI, M. E. Qualidade fisiológica de sementes de soja submetidas ao hidrocondicionamento. Acta Scientarium Agronomy, v.30, suplem., p.711-717, 2008 .

GURGEL JÚNIOR, F.E.; TORRES, S.B.; OLIVEIRA, F.N.; NUNES, T.A. Condicionamento fisiológico de sementes de pepino. Revista Caatinga, v.22, n.4, p.163$168,2009$.

KIKUTI, A.L.P.; KIKUTI, H.; MINAMI, K. Condicionamento fisiológico em sementes de pimentão. Revista Ciência Agronômica, v.36, n.2, p.243-248, 2005.

LIMA, L.B.; MARCOS FILHO, J. Condicionamento fisiológico de sementes de pepino e relação com desempenho das plantas em campo. Revista Brasileira de Sementes, v.31, n.3, p.27-37, 2009.

MARCOS FILHO, J. Fisiologia de sementes de plantas cultivadas. Piracicaba: Fealq, 2005. 495p.

MARCOS FILHO, J.; KIKUTI, A.L.P. Condicionamento fisiológico de sementes de couve-flor e desempenho das plantas em campo. Horticultura Brasileira, v.26, n.2, p.165-169, 2008.

MAGUIRE, J.D. Speed of germination-aid in selection and evaluation for seedling emergence and vigor. Crop Science, v.2, n.2, p.176-177, 1962.

MEDEIROS, M.A.; GRANGEIRO, L.C.; TORRES, S.B.; FREITAS, A.V.L. Maturação fisiológica de sementes 
de maxixe (Cucumis anguria L.). Revista Brasileira de Sementes, v.32, n.3, p.17-24, 2010.

MOTTA, C.A.P.; SILVA, W.R. Efeito de hidratação e desidratação no desempenho fisiológico de sementes de trigo. Pesquisa Agropecuária Brasileira, v.32, n.4, p.379390, 1997.

NAKAGAWA, J. Testes de vigor baseados na avaliação das plântulas. In: VIEIRA, R.D.; CARVALHO, N.M. (Ed.). Testes de vigor em sementes. Jaboticabal: FUNEP/ UNESP, 1994. p.49-86.

NAKAGAWA, J. Testes de vigor baseados nos desempenhos das plântulas. In: KRZYZANOWSKI, F.C.; VIEIRA, R.D.; FRANÇA NETO, J.B. (Ed.). Vigor de sementes: conceitos e testes. Londrina: ABRATES, 1999. p.2.1-2.24.

NASCIMENTO, W.M. Condicionamento osmótico de sementes de hortaliças visando a germinação em condições de temperaturas baixas. Horticultura Brasileira, v.23, n.2, p.211-214, 2005.
NASCIMENTO, W.M.; ARAGÃO, F.A.S. Condicionamento osmótico de sementes de melão: absorção de água e germinação sob diferentes temperaturas. Revista Brasileira de Sementes, v.24, n.1, p.153-157, 2002.

NERY, M.C. Aspectos morfofisiológicos do desenvolvimento de sementes de Tabebuia serratifolia Vahl Night. 2005. 95f. Dissertação (Mestrado em Fitotecnia) - Universidade Federal de Lavras, Lavras. 2005

PEÑAZOLA, A.P.S.; EIRA, M.T.S. Hydration-dehydration treatments on tomato seeds (Lycopersicon esculentum Mill.). Seed Science and Technology. v.21, n.1, p.309316, 1993.

PEREIRA, M.D.; DIAS, D.C.F.S.; DIAS, L.A.S.; ARAÚJO, E.F. Primed carrot seeds performance under water and temperature stress. Scientia Agricola, v.66, n.2, p.174-179, 2009.

TRIGO, M.F.O.O.; NEDEL, J.L.; LOPES, N.F.; TRIGO, L.F.N. Osmocondicionamento de sementes de cebola (Allium cepa L.) com soluções aeradas de polietilenoglicol. Revista Brasileira de Sementes, v.21, n.1, p.145-150, 1999. 